Hydrol. Earth Syst. Sci., 17, 1205-1215, 2013

www.hydrol-earth-syst-sci.net/17/1205/2013/

doi:10.5194/hess-17-1205-2013

(C) Author(s) 2013. CC Attribution 3.0 License.

\title{
Local and global perspectives on the virtual water trade
}

\author{
S. Tamea ${ }^{1}$, P. Allamano ${ }^{1}$, J. A. Carr ${ }^{2}$, P. Claps ${ }^{1}$, F. Laio ${ }^{1}$, and L. Ridolfi ${ }^{1}$ \\ ${ }^{1}$ Department of Environmental, Land and Infrastructure Engineering, Politecnico di Torino, Turin, Italy \\ ${ }^{2}$ Department of Environmental Sciences, University of Virginia, Charlottesville, Virginia, USA \\ Correspondence to: S. Tamea (stefania.tamea@polito.it)
}

Received: 29 October 2012 - Published in Hydrol. Earth Syst. Sci. Discuss.: 14 November 2012

Revised: 18 February 2013 - Accepted: 5 March 2013 - Published: 19 March 2013

\begin{abstract}
Recent studies on fluxes of virtual water are showing how the global food and goods trade interconnects the water resources of different and distant countries, conditioning the local water balances. This paper presents and discusses the assessment of virtual water fluxes between a single country and its network of trading partners, delineating a country's virtual water budget in space and time (years 19862010). The fluxes between the country under study and its importing/exporting partners are visualized with a geographical representation shaping the trade network as a virtual river/delta. Time variations of exchanged fluxes are quantified to show possible trends in the virtual water balance, while characterizing the time evolution of the trade network and its composition in terms of product categories (plantbased, animal-based, luxury food, and non-edible). The average distance traveled by virtual water to arrive to the place of consumption is also introduced as a new measure for the analysis of globalization of the virtual water trade.

Using Italy as an example, we find that food trade has a steadily growing importance compared to domestic production, with a major component represented by plant-based products, and luxury products taking an increasingly larger share (26\% in 2010). In 2010 Italy had an average net import of $55 \mathrm{~km}^{3}$ of virtual water $\left(38 \mathrm{~km}^{3}\right.$ in 1986), a value which poses the country among the top net importers in the world. On average each cubic meter of virtual water travels nearly $4000 \mathrm{~km}$ before entering Italy, while export goes to relatively closer countries (average distance: $2600 \mathrm{~km}$ ), with increasing trends in time which are almost unique among the world countries. Analyses proposed for Italy are replicated for 10 other world countries, triggering similar investigations on different socio-economic actualities.
\end{abstract}

\section{Introduction}

The virtual water content of a good is defined as the amount of water necessary for its production. Since its proposal (Allan, 1998), the concept of virtual water has been a key feature for the scientific comparison of the water consumption of different goods (e.g., plant food, meat, textile fibers, biofuels, etc.). The impact of different categories of goods on the available water resources can be determined by simply summing up their virtual water content, enabling the assessment of the overall impact of product categories or specific populations, defining their so-called water footprint. The global trade in all goods can also be translated into a corresponding virtual water trade, allowing quantification of the import and export fluxes of virtual water, and separating countries which import virtual water to sustain their population from countries which are net exporters of virtual water, e.g. produce more than needed for domestic consumption. In this sense, the concept of virtual water also provides a novel quantitative framework for the study of water resources used for agriculture and livestock production worldwide, and the water exchanges hidden in the food trade. In addition to this aspect, by calculating the virtual water content of various goods, scientists have highlighted the enormous volumes of water needed for their production, in particular for food products. For instance, on average in the period 1996-2005, the global water footprint (total amount of consumed virtual water) has been as large as $9087 \mathrm{~km}^{3}$ per year (Hoekstra and Mekonnen, 2012). A large part of this virtual water is transferred among regions of the world by global trade: in 2010 this trade has involved nearly $3000 \mathrm{~km}^{3}$ of virtual water, with a twofold increase over 1986. These numbers indicate that the virtual water consumption, dominated by food products, exceeds by an order of magnitude the water used by people for drinking 
and domestic usage, confirming the large impact of virtual water on the local and global water balance.

Due to its economical, social, political, and environmental implications, virtual water trade has attracted a growing amount of attention from the scientific community in the last decade (e.g., Hoekstra and Chapagain, 2008; Hoekstra and Mekonnen, 2012). Databases are now available reporting the virtual water content of hundreds of goods differentiated on the basis of the area of production. Such data availability allows for elucidation of some key characteristics of virtual water consumption and trade, including the remarkable differences among countries, the strong predominance of net importers that rely on just a few exporting countries, and the impact of agricultural policies and technologies (e.g., Hoekstra and Chapagain, 2008). Virtual water trade has been studied by using the tools of the complex network theory (Barrat et al., 2008), highlighting clues of smallworld behavior (Shutters and Muneepeerakul, 2012), the occurrence of hubs and rich-club effect (Suweis et al., 2011), and the existence of a community structure (D'Odorico et al., 2012). Similarly, the study of the temporal evolution of the virtual water network (Carr et al., 2012; Dalin et al., 2012; D'Odorico et al., 2012) has shown the progressive intensification of the virtual water exchanges, and of the geography of these variations.

Notwithstanding these achievements, the study of virtual water trade is, in some ways, just beginning. In fact, the complexity and the possible implications are far from being fully explored, and further efforts are needed to better understand the information content of the available data. In this paper, we tackle the problem by looking at the global network of virtual water from the point of view of a single country (hence the local component of our approach). Other works have analyzed the virtual water balance of a single region or country (e.g., Aldaya et al., 2010; Bulsink et al., 2010; Feng et al., 2011). However, our main goal is to propose innovative country-based analyses and data visualization tools which are capable of detecting and investigating new features of the virtual water trade. Such original tools are then applied to the case of Italy and used to quantify variations in time of the virtual water traded and consumed by the country. Results enable additional and novel insights on the virtual water budget of Italy (a country which has not been considered singularly in previous country-based works, such as those mentioned above), but the tools proposed in this paper are general and can be applied to similarly investigate any individual country (for other examples, see the Supplement Sect. B).

\section{Methods}

We collected food production and international trade data for the period 1986-2010 from the FAOSTAT database, developed by the Food and Agricultural Organization of the United Nations. 309 crops and animal products were considered, including all items with an available estimate of the country-specific virtual water content from Mekonnen and Hoekstra (2011): for any product $m$, the virtual water content (or water footprint) is obtained by considering the volume of water needed to produce $m$ in a given country, including the contributions of rainfall (green water), surface water and groundwater (blue water). We excluded from our calculations the grey water, which is an indicator of freshwater pollution, due to the strong uncertainties inherent in its determination (e.g., Hoekstra et al., 2011). The total number of countries considered, $N$, is equal to 253 ; since the number of active countries varies in time (e.g., 208 in 1986 and 211 in 2010), values corresponding to inactive countries in any given year are set to zero. The reported data were rectified to political changes over the $25 \mathrm{yr}$ period to allow comparison among different years. Political rectification regarded Ethiopia, Eritrea, Germany, Yemen, countries from ex-Yugoslavia, countries from the ex-Soviet union, Czech Republic and Slovakia, as reported in detail by Carr et al. (2013). Virtual water data for countries not reported in the estimates by Mekonnen and Hoekstra (2011) are based on the green and blue virtual water contents of the nearest neighbor ( $\pm 10^{\circ}$ of latitude and longitude). The global average values for the green and blue virtual water contents of product $m$ were used for countries with no close neighbor. For a part of the present analysis, products were further segregated into four categories: edible crops, edible animal products, edible luxury items (such as sugars, coffee and chocolate) and nonedible commodities (such as plant fibers, oil cakes or animal hides), as detailed in the Supplement Sect. A. Live animal weights were converted to live animal equivalents (heads) based on FAOSTAT datasets (http://www.fao.org/fileadmin/ templates/ess/documents/methodology/tcf.pdf).

FAOSTAT data provide for each product, $m$, and year, $t$, the amounts produced in any given country; these amounts multiplied by the corresponding local virtual water contents, give the $(N \times 1)$ vector of equivalent consumptions of virtual water for food production, $P_{m}(t)$. By summing up over nonoverlapping products, one obtains the vector of the total virtual water consumption (for production), $P(t)=\sum_{m} P_{m}(t)$. Non-overlapping products are a subset of the 309 items chosen to avoid double accounting of virtual water in primary and derived food commodities. Details are reported in the Supplement Sect. A. An analogous procedure was followed to obtain the virtual water fluxes among countries: for each product, $m$, and year, $t$, a $(N \times N)$ trade matrix, $T_{m}(t)$, was generated, where the $(i, j)$ element of the matrix is the export of that product from country $i$, to country $j$. Each individual trade matrix was then converted to a product-specific virtualwater trade matrix, $C_{m}(t)$, by multiplying each product quantity by the virtual water content of such product in the country of origin. The total virtual water trade matrix is simply $C(t)=\sum_{m} C_{m}(t)$ where, in this case, summation extends to all 309 items because double-accounting problems do not affect trade data. 
Table 1. Volumes of virtual water imported and exported by Italy in 1986 and 2010 grouped by world regions (in $\mathrm{km}^{3} \mathrm{yr}^{-1}$ ) and percentage variation in time. Percentages in the import/export columns (in italic) are calculated with respect to the total value in the last row.

\begin{tabular}{|c|c|c|c|c|c|c|c|c|c|c|}
\hline \multirow[b]{2}{*}{ Europe } & \multicolumn{2}{|c|}{$\begin{array}{c}\text { IMPORT } \\
1986\end{array}$} & \multicolumn{2}{|c|}{$\begin{array}{c}\text { IMPORT } \\
2010\end{array}$} & \multirow{2}{*}{$\begin{array}{r}\text { Var. \% } \\
(2010-1986) \\
+94\end{array}$} & \multicolumn{2}{|c|}{$\begin{array}{c}\text { EXPORT } \\
1986\end{array}$} & \multicolumn{2}{|c|}{$\begin{array}{c}\text { EXPORT } \\
2010\end{array}$} & \multirow{2}{*}{$\begin{array}{r}\text { Var. \% } \\
(2010-1986) \\
+298\end{array}$} \\
\hline & 28.2 & $56 \%$ & 54.6 & $60 \%$ & & 6.7 & $56 \%$ & 26.5 & $72 \%$ & \\
\hline Asia & 4.5 & $9 \%$ & 11.7 & $13 \%$ & +160 & 1.2 & $10 \%$ & 5.0 & $13 \%$ & +322 \\
\hline Africa & 5.9 & $12 \%$ & 8.2 & $9 \%$ & +39 & 2.7 & $23 \%$ & 1.5 & $4 \%$ & -45 \\
\hline North America & 6.6 & $13 \%$ & 4.8 & $5 \%$ & -28 & 0.9 & $7 \%$ & 3.0 & $8 \%$ & +235 \\
\hline South America & 4.5 & $9 \%$ & 11.4 & $12 \%$ & +150 & 0.4 & $4 \%$ & 0.33 & $0.9 \%$ & -24 \\
\hline Oceania & 0.58 & $1.2 \%$ & 0.87 & $1.0 \%$ & +50 & 0.06 & $0.5 \%$ & 0.55 & $1.5 \%$ & +875 \\
\hline Total & 50.3 & $100 \%$ & 91.4 & $100 \%$ & +82 & 12.0 & $100 \%$ & 36.8 & $100 \%$ & +208 \\
\hline
\end{tabular}

\section{Results and discussion}

The international trade of food entails the displacement of the virtual water embedded in the traded food products. Thus, food trade generates a "flow" of virtual water from exporting to importing countries in a global network connecting the world's countries. While the virtual water network has already been analyzed under a global perspective (e.g., Suweis et al., 2011; Carr et al., 2012; Dalin et al., 2012), in this paper we propose a novel approach which aims at drawing general conclusions starting from a local view of the network to draw, i.e. focusing on the flows and water budget of specific countries. We take Italy as a paradigmatic example to show the increased knowledge which can be gained by analyzing the virtual water network from a local perspective. Examples pertaining to other countries are reported in the Supplement Sect. B to demonstrate the general applicability of the proposed tools. The Supplement refers to a selection of ten countries (Australia, Brazil, China, Egypt, France, Germany, India, Indonesia, Japan, and USA) covering all continents, a large portion of the global population (more than $50 \%$ in 2010), and a wide range of socio-economic and cultural actualities.

\subsection{Network-related analyses}

Considering first the virtual water flows associated with the import of goods, the volumes (per year) imported by Italy from each country are represented as river branches originating from the center of the supplying country. All branches are then connected in the form of a (virtual) river network, grouping all flows into a single effluent representing the total Italian import in a given year. Such representation, although not based on the direct connections between Italy and the trading partners, allows for a graphical comparison of flows from different region or continents, also quantified in the following Table 1. The virtual river is shown in Fig. 1 for year 2010.

In 2010 Italy imported $91.4 \mathrm{~km}^{3}$ of virtual water from 156 countries in all continents, but primarily from Europe. The import network evolved in time, as emerges from the inset in Fig. 1 and from the analysis of Table 1 . The network structure underwent only minor modifications between 1986 and 2010, with a small increase (14 links) in the number of supplier countries: some of these changes were caused by the political/administrative changes in countries such as the former USSR and Yugoslavia, while some other links - e.g. with remote islands of the Indian and Pacific Ocean - were nonpermanent and switched on and off irregularly, depending on the year. The overall incoming flux increased by $82 \%$ from 1986 to 2010; some major changes can be found in the Americas: North and Central America decreased their contribution (from 6.6 to $4.8 \mathrm{~km}^{3}$ ), while South America strongly increased it (from 4.1 to $11.4 \mathrm{~km}^{3}$ ); similarly, Asia underwent stronger-than-average increases in the study period.

We report in Table 2 some exchange values for the selection of countries reported in the Supplement Sect. B as relevant examples. France remains the preferred importing partner for Italy, but the increase in the imported flux is weaker than the world average $(82 \%)$. The USA are losing their share in the Italian import of food, while in contrast, Brazil and Indonesia are taking a leading role, with impressive increase rates in the last years. As of export, Italy has strongly increased its virtual water export to the USA, exceeding the corresponding import flux. Italian products have also relevantly increased their penetration into the Chinese, Japanese and Australian markets, while fluxes to India and Indonesia remained negligible. On the contrary, Egypt and Brazil have dramatically decreased their imports from Italy to the point that they have become nearly negligible.

A reversed spatial representation, resembling a river delta, can be used to visualize the virtual water flows associated with exports from Italy (Fig. 2). In this case the end-point of each branch represents the recipient countries, and the source represents the total Italian export in a given year. The river delta, as well as the virtual river in Fig. 1, is not meant to represent a network structure but to provide a graphical representation of virtual water flows aggregated by region or continent. 


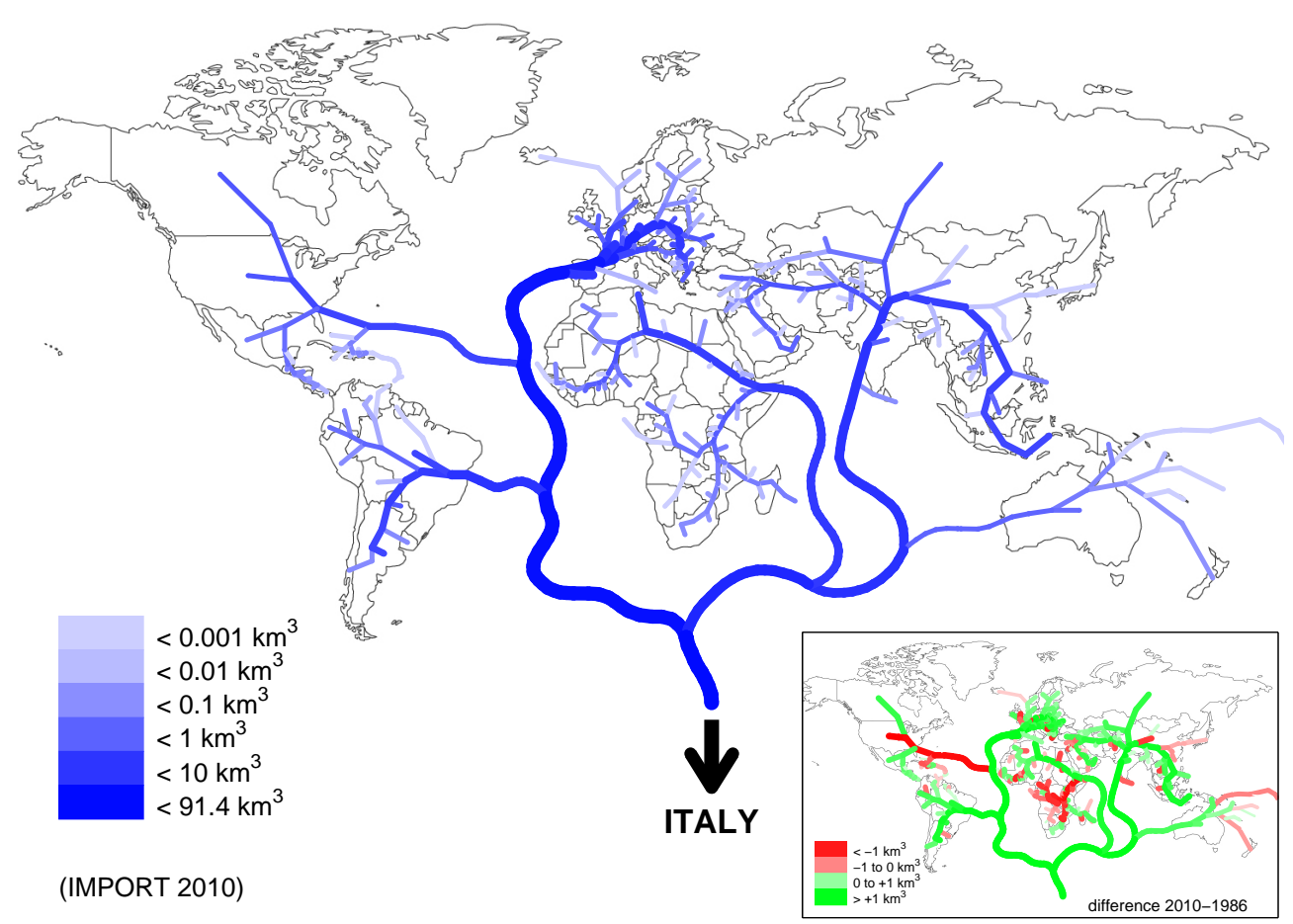

Fig. 1. The virtual water river flowing to Italy in 2010: branches originate in the trading countries and line thicknesses and colors indicate the virtual water volumes imported by Italy. Differences in import fluxes between 2010 and 1986 are reported in the inset.

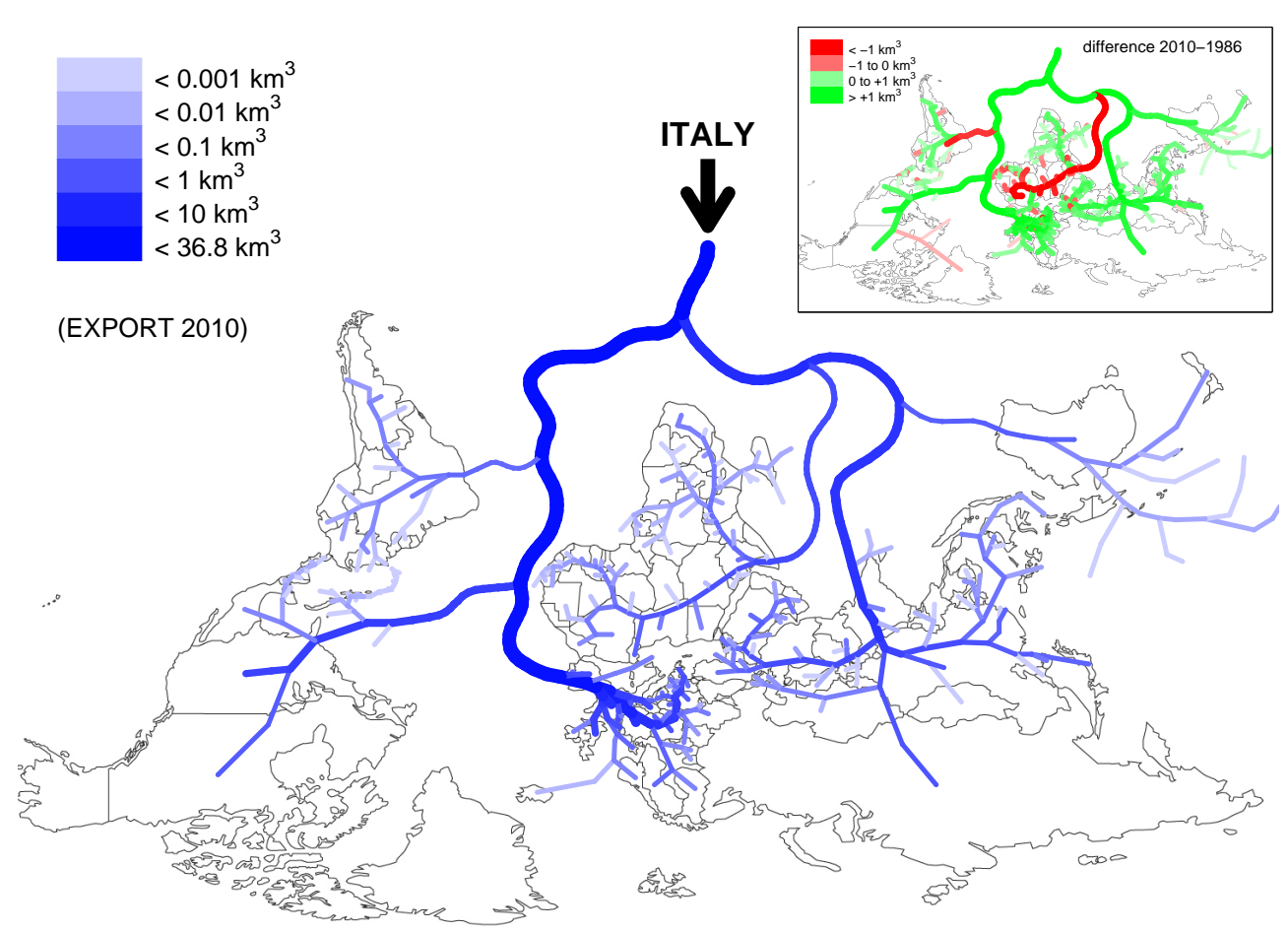

Fig. 2. The virtual water delta draining water from Italy in 2010: branches terminate in the trading countries and line thicknesses and colors indicate the virtual water volumes exported by Italy. Differences in export fluxes between 2010 and 1986 are reported in the inset. 
Table 2. Volumes of virtual water imported/exported by Italy in 1986 and 2010 from/to specific countries (in $\mathrm{km}^{3} \mathrm{yr}^{-1}$ ) and (in italic) positions of each country in the ranking for the major volumes exchanged with Italy in the two years.

\begin{tabular}{lrrrrrrrr}
\hline & \multicolumn{2}{c}{ IMPORT } & \multicolumn{2}{c}{ IMPORT } & \multicolumn{2}{c}{ EXPORT } & \multicolumn{2}{c}{ EXPORT } \\
& \multicolumn{2}{c}{1986} & \multicolumn{2}{c}{ 2010 } & \multicolumn{2}{c}{1986} & \multicolumn{2}{c}{2010} \\
\hline Australia & 0.47 & $\# 25$ & 0.59 & $\# 31$ & 0.06 & $\# 31$ & 0.48 & $\# 17$ \\
Brazil & 2.37 & $\# 5$ & 4.37 & $\# 4$ & 0.40 & $\# 8$ & 0.13 & $\# 39$ \\
China & 0.47 & $\# 26$ & 0.21 & $\# 49$ & 0.05 & $\# 32$ & 0.80 & $\# 13$ \\
Egypt & 0.24 & $\# 33$ & 0.10 & $\# 68$ & 0.30 & $\# 10$ & 0.08 & $\# 54$ \\
France & 8.94 & $\# 1$ & 10.82 & $\# 1$ & 1.96 & $\# 1$ & 5.23 & $\# 2$ \\
Germany & 3.70 & $\# 4$ & 9.02 & $\# 3$ & 1.63 & $\# 2$ & 5.44 & $\# 1$ \\
India & 0.26 & $\# 32$ & 1.18 & $\# 21$ & 0.003 & $\# 85$ & 0.10 & $\# 48$ \\
Indonesia & 0.97 & $\# 15$ & 4.14 & $\# 6$ & 0.002 & $\# 96$ & 0.03 & $\# 73$ \\
Japan & 0.003 & $\# 103$ & 0.002 & $\# 119$ & 0.07 & $\# 30$ & 0.45 & $\# 20$ \\
USA & 4.89 & $\# 2$ & 1.98 & $\# 12$ & 0.74 & $\# 4$ & 2.19 & $\# 3$ \\
\hline
\end{tabular}

The total Italian export in 2010 is $36.8 \mathrm{~km}^{3}$ of virtual water and more than $70 \%$ of this flux is directed to European countries. The total number of receiving countries is 189 in 2010, with an increase with respect to 1986 of 21 links. The time evolution of the export volumes has been even stronger than for the import: the overall flux in the delta was 12.0 $\mathrm{km}^{3}$ in 1986, which is one third of the flux in 2010. The change in the different world regions has not been homogeneous: Asia, Oceania and North America have tripled (or more) their import from Italy, while Africa and South America slightly decreased it. Exports to other European countries (Table 1) overall increased from 6.7 to $26.5 \mathrm{~km}^{3}$. Such a difference highlights the effects of the European Union's internal market, which was enlarged and strengthened over the course of the study period. Since Europe represents the preferred source and destination for the Italian virtual water, we reported in Fig. 3 a representation of the net fluxes (import minus export) from European countries in 2010.

It is clear from Fig. 3 that Italy tends to import virtual water from Mediterranean countries and from countries in central and eastern Europe, while the net flux is reversed (i.e., the export dominates) for northern European and Balkan countries. Germany and France are Italy's preferred export trade partners, with Germany taking the leading role in more recent years (Table 2), although the net flux of virtual water is still directed toward Italy (import greater than export).

Virtual rivers and deltas are depicted in the Supplement Sect. B for the ten selected countries, showing how they change when looking at the overall network trade from the point of view of different countries and how the relative importance of different branches (e.g. continent-aggregated fluxes) are modified by the country-specific major fluxes.

\subsection{Virtual water balance}

The time evolution of the virtual water network trade is now analyzed in a more extended and detailed way. Annual volumes of virtual water imported, exported and used for

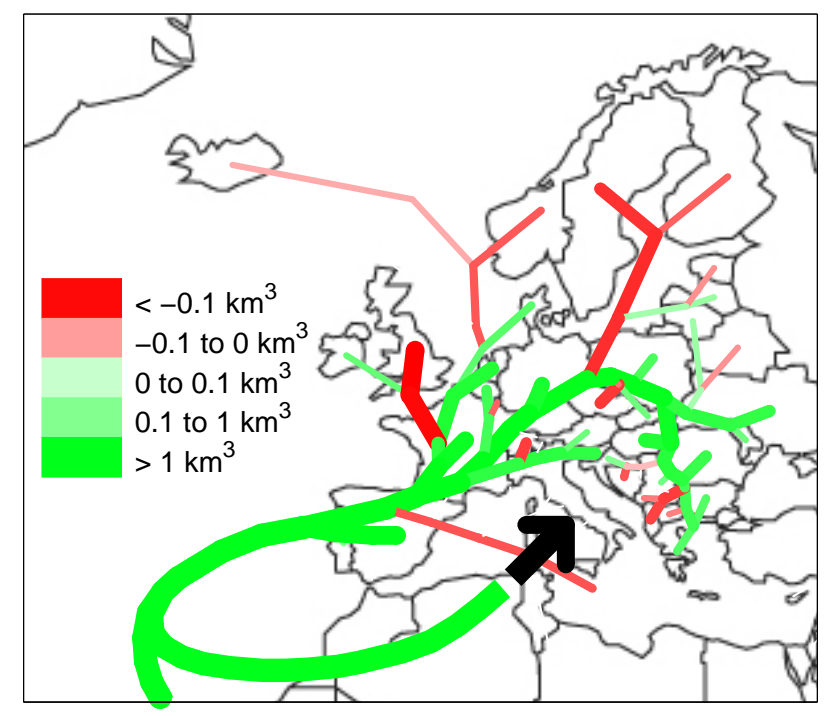

Fig. 3. Net virtual water fluxes (import minus export) from European countries to Italy in 2010.

production inside Italy are computed for the 1986-2010 period (Fig. 4).

The volumes exchanged with foreign countries have increased regularly with time in the last few decades: the increase in export has been continuous and smooth in time, while import had some fluctuations in the most recent years. Production, on the contrary, remained constant until the last decade, when it began a weak but clear decrease. In the time span considered, Italy has sensibly increased its dependence on the international market: if in 1986 the contribution of internal production to the virtual water balance was larger than import, in 2010 the situation is reversed, with down-crossing occurring after year 2000. Given the relationship among the water balance components (in the absence of storage),

Import + Production $=$ Export + Consumption,

the domestic consumption results in a weakly increasing trend between 110 and $120 \mathrm{~km}^{3} \mathrm{yr}^{-1}$ (not shown). Such volumes are much greater than volumes used for internal production, confirming the strong dependence of the country on international virtual water import. Clearly not all consumption comes from import (and not all production goes into export), because Italian processing industries are often based on import-export, importing raw materials and exporting processed products.

Virtual water used for internal production (mainly crop growth) remained approximately constant in time even though harvested area in Italy reduced of more than $20 \%$ (from 127 to 97 thousands $\mathrm{km}^{2}$ ) in the period 1986-2010 (FAOSTAT data). This decrease was slightly compensated by an increase in crop yield (agricultural production per unit surface), still resulting in a strongly decreasing volume of agricultural production. The negative trend of production is 


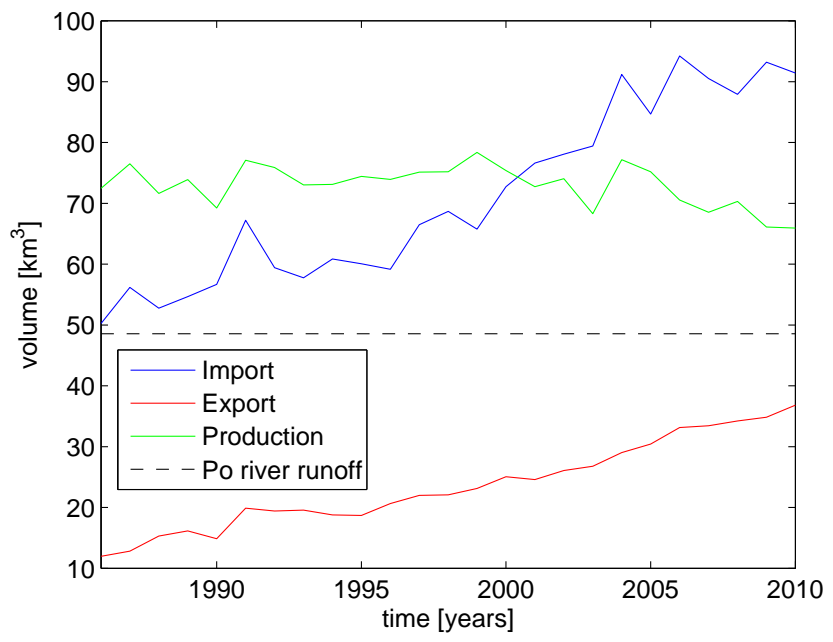

Fig. 4. Variation in time of the virtual water volumes imported, exported and used for food production in Italy and comparison with the average annual flow of the Po river.

compensated by the large increase of some crops, such as maize and olives, whose associated virtual water contributes in keeping an almost constant virtual water use for internal production.

Comparing the volumes of virtual water with the average annual flow of the major Italian river, the Po river $\left(1540 \mathrm{~m}^{3} \mathrm{~s}^{-1}\right.$ or $\left.48.6 \mathrm{~km}^{3} \mathrm{yr}^{-1}\right)$, one can state that in 2010 Italy employed for food production a volume of water which is around 1.5 times the annual flow in the Po river, while the Italian import of virtual water was almost twice the Po river's annual flow. To better comprehend this comparison, consider that the catchment of the Po river at the mouth covers almost one fourth of the whole surface of Italy, and that $48.6 \mathrm{~km}^{3} \mathrm{yr}^{-1}$ of water corresponds to almost half of the total runoff production in Italy, which has been estimated to be $104 \mathrm{~km}^{3} \mathrm{yr}^{-1}$ (this figure was estimated through a multiple regression analysis on 300 catchments, including rainfall and Budyko index as explanatory variables). Also note that, of course, not all water flowing in a river can be withdrawn for human use: the Po catchment, which is already intensely exploited in terms of water resources, has a $22 \mathrm{~km}^{3} \mathrm{yr}^{-1}$ of water withdrawn for agricultural, industrial, and domestic usage (Montanari, 2012). As such, the $\sim 90 \mathrm{~km}^{3}$ of water imported by Italy in 2010 is an impressive figure, demonstrating that the Italian water consumption is not sustainable with the domestic resources only.

The country overviews in the Supplement Sect. B show that the virtual water import of France is similar to that of Italy, while the export is greater and comparable to the import across the whole time span. Germany had similar values to Italy in 1986 but its virtual water import and export increased at a faster pace in the last decades. Internal productions in the three countries are comparable, relatively constant, and all in the same order of magnitude as the trading fluxes. On the

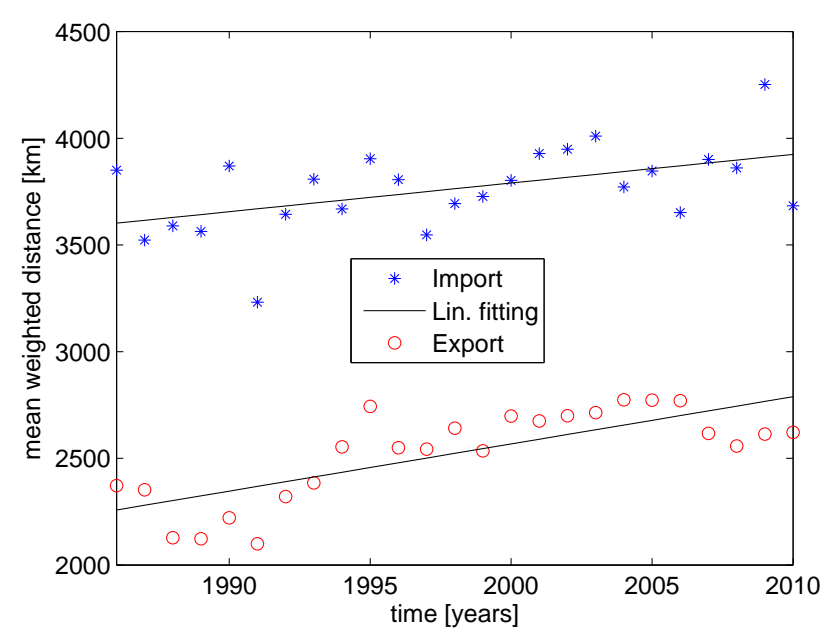

Fig. 5. Variation in time of the mean distance travelled by virtual water entering Italy (import) or flowing out of Italy (export).

contrary, in emerging countries, such as Brazil, China, India and Indonesia, the virtual water for national production is (much) larger than the exchanged fluxes which, however, are increasing at a high rate.

To make the comparison of Italy with other countries more general, we consider the virtual water flows of all countries in the world during 1986 and 2010. We sort countries by decreasing net import (import minus export) flux and find that Italy held the 3rd position in 1986 and the 5th position in 2010 , confirming that Italy is among the largest importers of virtual water in the world. If the sorting is repeated according to the net per-capita import, one finds that Italy ranks only between 48th and 49th, because in this case the smallest countries tend to have higher net imports per capita. In fact, accumulating the population living in the countries with percapita net import higher than Italy (e.g., 48 countries in 1986 and 47 in 2010), this adds up to only $1 \%$ to $3 \%$ of the global population, demonstrating that the vast majority of the world population has a per-capita net import of virtual water lower than the average Italian. A similar analysis can be carried out by considering the virtual water per capita production: in this case, Italy occupies the 113th position in 1986 and the 140th in 2010, with respectively $34 \%$ and $41 \%$ of the global population having a larger per-capita production than the average Italian.

\subsection{Distance-based analyses}

In addition to the spatial distribution of virtual water flows exchanged by Italy, it is interesting to analyze the distances of the origin/destination countries. We computed the geographical distance between Italy and countries of origin and destination by considering the distance among the most populated cities of each country (based on the CEPII dataset www.cepii.fr); each distance is weighted by the volumes of 


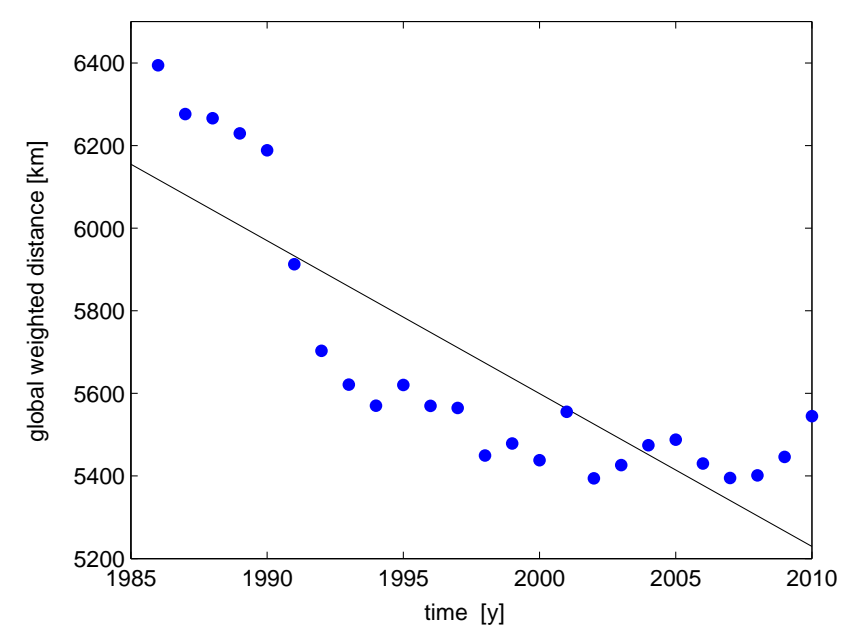

Fig. 6. Variation in time of the mean distance travelled by a generic unit of virtual water exchanged worldwide.

virtual water respectively imported and exported, to obtain a measure of the average distance travelled by a unit volume of virtual water exchanged by Italy with the rest of the world. Figure 5 depicts the average weighted distances of origin/destination countries across the years, from 1986 to 2010. The weights are calculated considering the strength of each flux, divided by the total volumes imported or exported by Italy.

The average distance travelled by food and virtual water is greater for import than for export $(3700 \mathrm{~km}$ vs. $2600 \mathrm{~km}$ in 2010) and, both import and export distances increase in time (both increases are significant at a $5 \%$ level with the Student's $t$ test). Considering that the number of links with other countries had only a small increase in time (see Sect. 3.1), the explanation behind this behavior should be sought in a decrease of the flux exchanged with closer countries, and/or in an increase of the exchanged volumes with more distant countries. This second effect seems to be the dominant one: in fact, the exchanged volumes with closer countries (within $1500 \mathrm{~km}$ of Italy) remain nearly constant in time, while fluxes from farther countries (more than $10000 \mathrm{~km}$ from Italy) doubled their share of import (from $7 \%$ of the total flux in 1986 to $14 \%$ in 2010), and tripled their share of export (from $1 \%$ to $3 \%$ of the total flux). The Italian trade of food and related products is thus showing a clear tendency toward globalization, with relevant virtual water fluxes also to/from countries very distant from Italy.

In order to place these trends in a global context, we calculated the average weighted distance considering all links of the food trade network and represented the results in Fig. 6. Globally, the average distance travelled by virtual water worldwide has decreased in time, opposite to what happened to the virtual water exchanged by Italy. The decreasing trend is statistically significant (at a $5 \%$ level) and it can be explained partly by political/administrative changes (e.g.,
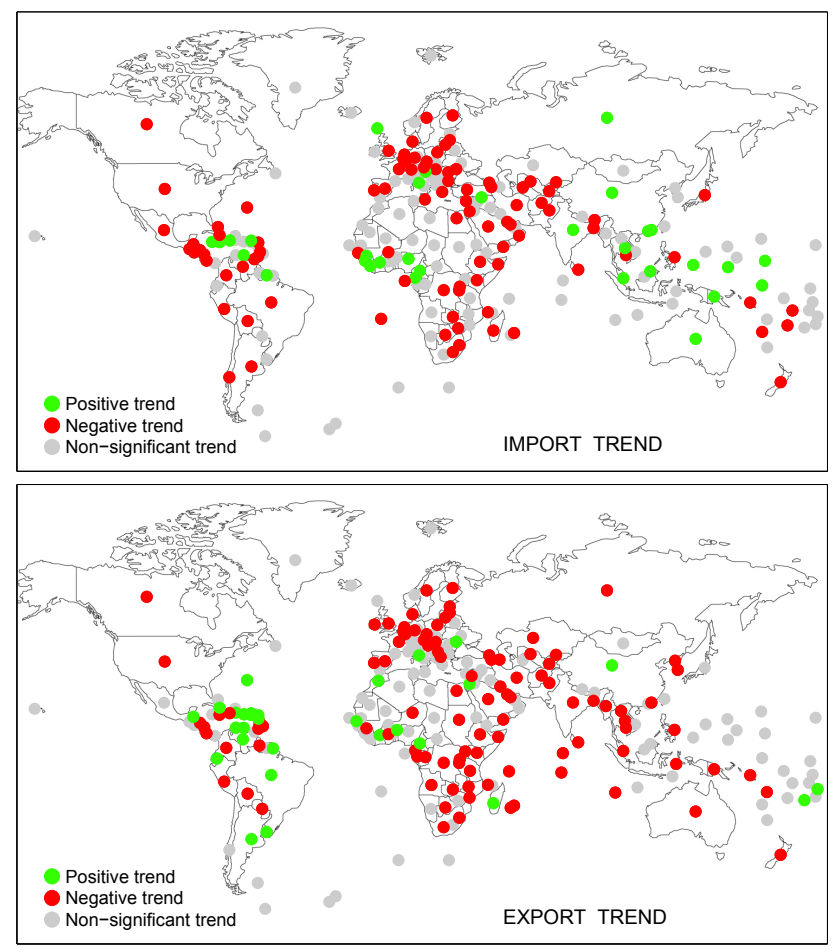

Fig. 7. Spatial representation of the trend signs for the mean distance travelled by virtual water imported (above) and exported (below) by each country from/to the rest of the world.

disgregation of former USSR) and partly by changes in the international trade (see Tamea et al., 2012, - author's comment - for further details). The general decrease of distances in the international virtual water trade, being the result of strengthening of closer connections to the detriment of farther connections, might be influenced by partitioned travels, where longer import and export distances are split into shorter stages, where goods are accounted as both import and export by the transit country. The reason why this fact should not apply to import/export of Italy, among others, is not clear.

When the country-specific distance analysis is repeated for other countries, we find that increasing trends seldom occur in countries similar to Italy in size, population or gross domestic product. Plots of weighted distances over time, as in Fig. 5, are presented in the Supplement Sect. B for the selected countries. Most of them reveal negative trends for both imports and exports (e.g., Egypt, France, Germany and USA). In some cases, import and export trends are opposite (e.g. Australia) or are not statistically significant at a $5 \%$ level in a Student's $t$ test (e.g., import distances of Indonesia or export trend of Japan). Only China has both significantly increasing trends, the same as Italy.

Extending the trend analysis to all countries in the world, one can flag on a world map the countries having positive, negative and non-significant trends, and look for geographical patterns (significance is at a $5 \%$ level). Figure 7 shows 

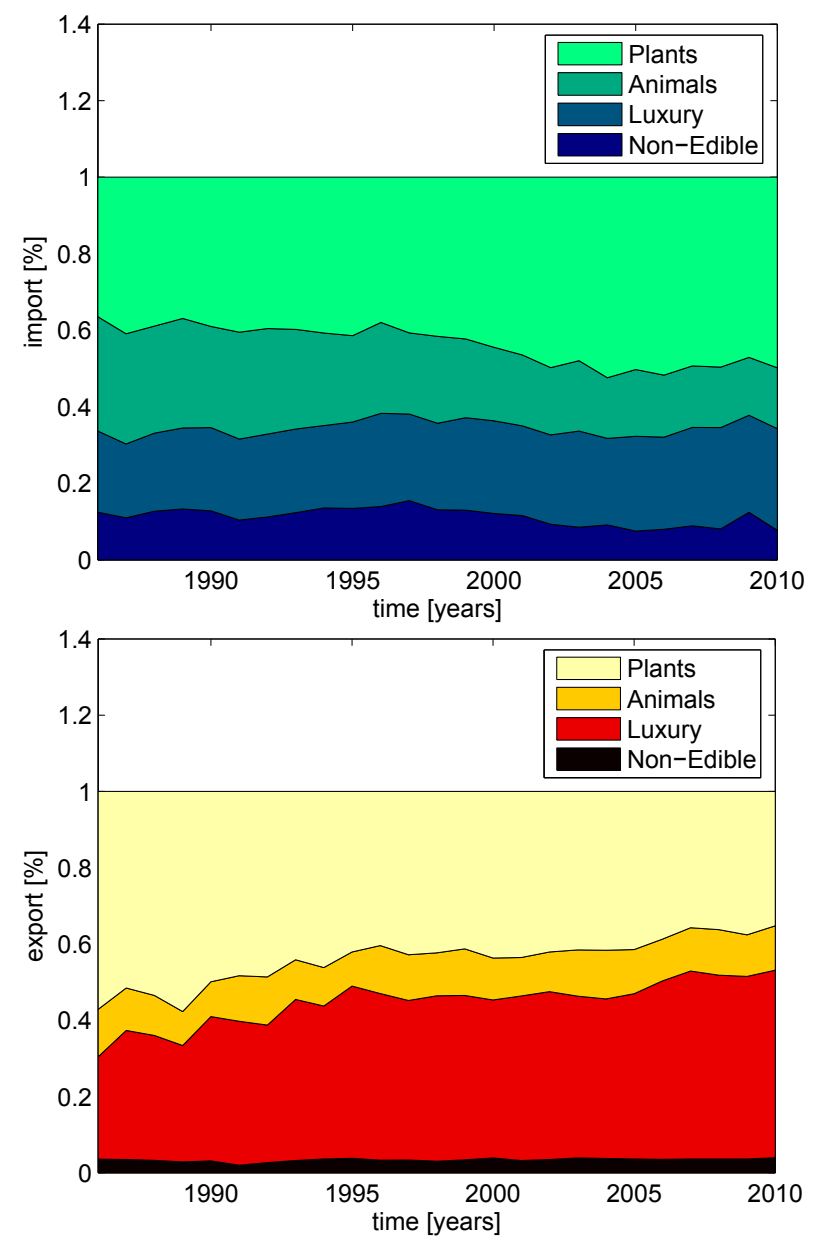

Fig. 8. Contributions of each category to the total volume of virtual water imported (upper panel) and exported (bottom panel) in the period 1986-2010.

such analysis for import and export, highlighting the marked presence of positive clusters around the Caribbean Islands, West/Central Africa, East Asia and Oceania (for import), and Central/South America (for export).

Selecting world countries with more than 1 million inhabitants and per-capita gross domestic product higher than 10000 USD (30 countries, considering average values in the time span), there are only 5 countries with positive import trend (Australia, Hong Kong, Italy, Singapore, and Slovenia) and only 3 countries with a positive export trend (Israel, Italy, and Puerto Rico). Italy is the only country with the above characteristics having significant trends in both import and export distances.

\subsection{Analyses by categories}

In the previous section, virtual water fluxes have been studied independently of which goods have generated them. However, interesting aspects emerge if the type of good originating the water flux is taken into account. To this aim, in this
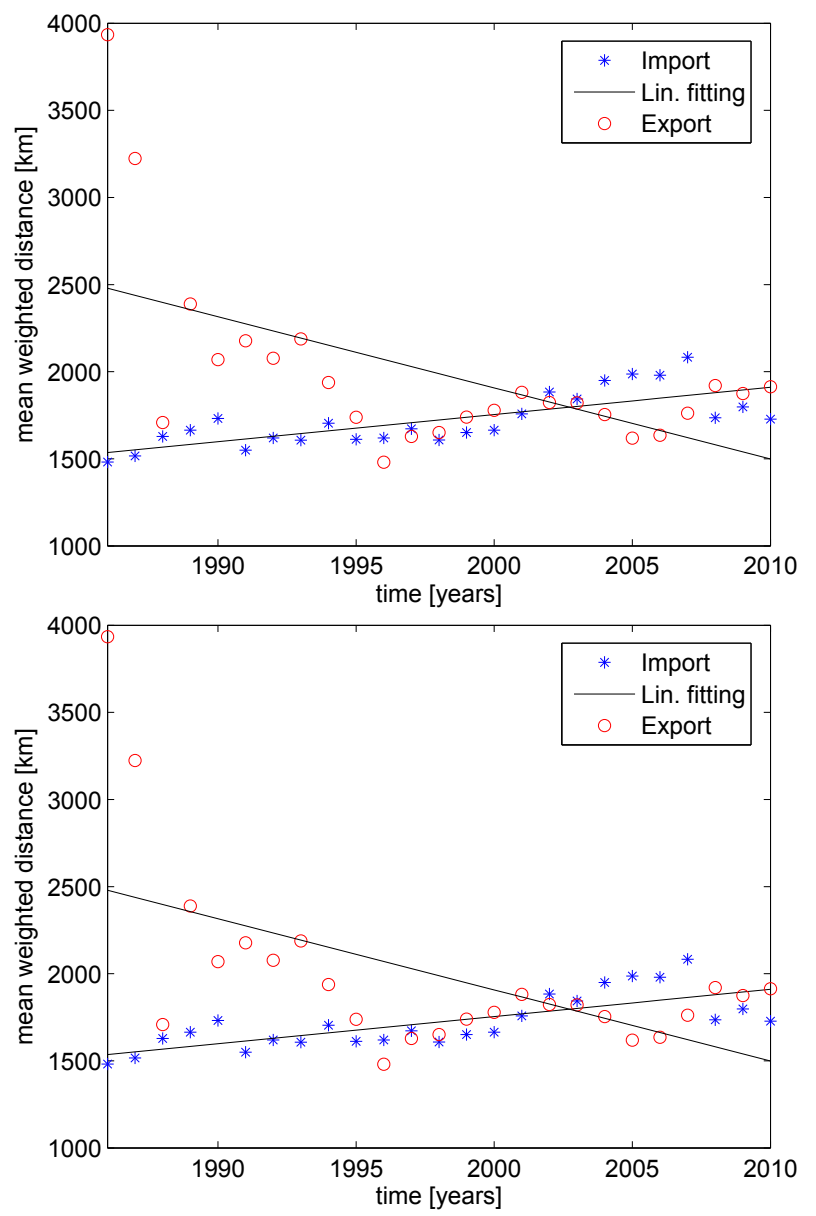

Fig. 9. Average distance travelled by virtual water associated to different categories of goods (upper panel: plant-based products, bottom panel: animal-based products).

section we select four main categories of goods and investigate the corresponding virtual water fluxes for Italy; categories are: plants, animals, luxury, and non-edible items (same as in Carr et al., 2013). The main results of this analysis are shown in Fig. 8 and Table 3. The former shows the temporal evolution of the contribution of each category to the total italian import and export of virtual water during the period 1986-2010, while the table reports the fluxes based on the continent in which the trading partners are located.

Some general features are evident. Firstly, plants are the main component of virtual water import throughout the study period. The relative importance of virtual water imports associated with plant products increases in time from $37 \%$ in 1986 to $50 \%$ in 2010 . In contrast, there has been a decrease in the percentage of virtual water import in animal products (from $30 \%$ in 1986 to $16 \%$ in 2010), possibly reflecting commercial and dietary changes resulting from health and safety campaigns. Notice that contraction in the percentage is quite steady in time and is contributed also by a decrease in the volume of animal-related virtual water import (and not 
Table 3. Volumes of virtual water imported/exported by Italy in 1986 and 2010 subdivided into categories of exchanged goods (in $\mathrm{km}^{3} \mathrm{yr}^{-1}$ ) from/to different world regions. Percentages (in italic) are calculated with respect to the total import (and export) of each year; " $<$ " indicates volumes lower than $0.01 \mathrm{~km}^{3}$.

\begin{tabular}{|c|c|c|c|c|c|c|c|c|}
\hline \multirow[t]{2}{*}{ IMPORT } & \multicolumn{2}{|c|}{ PLANTS } & \multicolumn{2}{|c|}{ ANIMALS } & \multicolumn{2}{|c|}{ LUXURY } & \multicolumn{2}{|c|}{ NON-EDIBLE } \\
\hline & 1986 & 2010 & 1986 & 2010 & 1986 & 2010 & 1986 & 2010 \\
\hline TOTAL & 18.3 & 43.6 & 15.0 & 13.9 & 10.7 & 23.3 & 6.2 & 7.1 \\
\hline (\% of total import) & $37 \%$ & $50 \%$ & $30 \%$ & $16 \%$ & $21 \%$ & $26 \%$ & $12 \%$ & $8 \%$ \\
\hline Europe & 8.2 & 17.3 & 14.3 & 13.1 & 4.4 & 14.6 & 1.3 & 2.8 \\
\hline Asia & 1.8 & 7.6 & 0.09 & $<$ & 0.6 & 2.2 & 1.9 & 1.8 \\
\hline Africa & 0.6 & 4.9 & $<$ & $<$ & 3.8 & 3.0 & 1.4 & 2.0 \\
\hline North America & 4.9 & 3.3 & 0.17 & 0.06 & 0.6 & 0.9 & 0.9 & 0.3 \\
\hline South America & 2.7 & 10.3 & 0.4 & 0.7 & 1.2 & 2.5 & 0.2 & 0.14 \\
\hline Oceania & 0.05 & 0.2 & 0.07 & 0.08 & $<$ & $<$ & 0.5 & 0.12 \\
\hline \multirow[t]{2}{*}{ EXPORT } & \multicolumn{2}{|c|}{ PLANTS } & \multicolumn{2}{|c|}{ ANIMALS } & \multicolumn{2}{|c|}{ LUXURY } & \multicolumn{2}{|c|}{ NON-EDIBLE } \\
\hline & 1986 & 2010 & 1986 & 2010 & 1986 & 2010 & 1986 & 2010 \\
\hline TOTAL & 6.8 & 12.4 & 1.5 & 4.1 & 3.2 & 16.5 & 0.4 & 1.2 \\
\hline (\% of total export) & $57 \%$ & $36 \%$ & $12 \%$ & $12 \%$ & $27 \%$ & $48 \%$ & $4 \%$ & $4 \%$ \\
\hline Europe & 3.0 & 8.2 & 0.8 & 3.5 & 2.6 & 12.4 & 0.3 & 0.8 \\
\hline Asia & 0.8 & 1.0 & 0.2 & 0.4 & 0.1 & 2.3 & 0.07 & 0.3 \\
\hline Africa & 2.5 & 1.0 & 0.08 & 0.07 & 0.1 & 0.4 & 0.03 & 0.09 \\
\hline North America & 0.5 & 1.9 & 0.05 & 0.14 & 0.3 & 0.9 & $<$ & 0.04 \\
\hline South America & 0.01 & 0.1 & 0.4 & $<$ & 0.02 & 0.2 & $<$ & $<$ \\
\hline Oceania & 0.02 & 0.15 & $<$ & 0.01 & 0.03 & 0.4 & $<$ & $<$ \\
\hline
\end{tabular}

only in their relative importance with respect to the other imports; see Table 3) in spite of the total water import having grown at great extent. In the last few years, the second largest contribution to virtual water imports was associated with luxury-related products (it was the third one in 1986), which exhibited a significant increase from $21 \%$ to $26 \%$ of total import.

When focusing on export, some structural differences with respect to import become clear. Plants dominated virtual water exports at the beginning of the study period (57\%), but underwent a remarkable reduction in the first decade (see Fig. 8) reaching in 2010 the $36 \%$ of virtual water export. Luxury products have become prevalent (from $27 \%$ in 1986 to $48 \%$ in 2010) and the growing trend seems to continue, even though at a weaker pace. The importance of this category testifies the existence of relevant processing food industries (e.g., wine, coffee, and confectionery industry) in Italy. Notice that in terms of virtual water volumes, Italian plant-related export was about $30 \%$ of import, while this percentage grows to $71 \%$ for luxury. Animal products are a minor component of virtual water exports from Italy when compared to plant and luxury products; however, differently from imports, no trends exist and the corresponding water export remains nearly constant around $12 \%$. Since Italian total virtual water export has grown in time (see Fig. 4), this entails that the virtual water component linked to animal export trade has grown proportionally (see Table 3).
Table 3 reports other interesting facts. For example, practically all animal-related virtual water is imported from Europe. The reduction of virtual water import from North America in the period 1986-2010 is due mainly to plants and (to a lesser extent) to non-edible items. The import of nonedible items increases from Europe, while the contribution from extra-European countries has decreased.

As for the virtual water export, the trade toward Europe has grown quite homogeneously in all categories, with luxury items and plants being the most important in terms of volume. Luxury products are the most relevant contributors to virtual water export to Europe, Asia, South America and Oceania, with a strong increase in the period 1986-2010.

A similar analysis was repeated for the selected countries in the Supplement Sect. B. In general it can be observed that the increase of the luxury quota shown in Fig. 8 represents a typical characteristic of the Italian case. Among the examples shown, in fact, a similar behavior is observed only for France, while the importance of the luxury quota is minor in the other cases. A high variability emerges in the time evolution of the animal and plant quotas, where countries like Australia and Brazil appear to be great exporters of both categories.

Finally, Fig. 9 shows the time behavior of the mean weighted distance for some categories. Plant-related trade displays the same trends and similar values as those discussed in the context of total virtual water trade (see Fig. 5). Differently, the typical distances of the animal-related virtual 
water trade are much lower: about $1 / 3$ and $2 / 3$ of the corresponding distances of plants items for import and export respectively, suggesting that a large share of Italian importation of animals originates in European countries. Also, the trend for export is decreasing (significantly at the $5 \%$ level), as opposed to the overall increasing trend (Fig. 5); clearly, associated volumes are not large enough to invert the overall trend.

Luxury-related and non-edible-related export distances (not shown) increase similarly to the case of plant products. In contrast, the corresponding import distances exhibit strong decreasing trends. This is coherent with data reported in Table 3 that show the increment of import from Europe.

\section{Conclusions}

The water footprint concept is quickly becoming a key tool to evaluate the impact of human activities on water resources and to highlight the huge amount of water virtually embedded in the global trade of goods. We have studied the virtual water trade by focusing on the interactions of a single country, Italy, with the global virtual water network and considered the temporal evolution in the period 1986-2010.

Coherently with the general behavior of the network, Italian import and export of virtual water have grown markedly ( $82 \%$ and $208 \%$, respectively). During the period analyzed, Italy remained among the largest importers of virtual water in the world with only $1-3 \%$ of the world population exhibiting per-capita net import higher than Italy. According to the country virtual water budget, the dependence on import has increased over the last decades and has overcome the internal production since year 2000. Italian import and export here visualized like a river (or a delta) that feeds (drains) virtual water to (from) Italy - are well developed and connect almost all world countries; fluxes on these networks are not static and important changes in time occur.

Italy has been shown to import virtual water from very distant countries with the mean distance travelled by virtual water being about $3800 \mathrm{~km}$ for imported and $2500 \mathrm{~km}$ for exported products; this mean distance has grown significantly in the last decades. Notably, in spite of trade globalization, the majority of countries show negative or no trend. If one subdivides the virtual water fluxes in categories (plants, animals, luxury and non-edible), a remarkable temporal decrease of animal-related virtual water import is found. In contrast, plant-related virtual water export has decreased in time, while a clear positive trend occurs for luxury goods.

Our analysis has demonstrated that the approach of integrating the local (country) perspective to the global perspective can shed new light on the virtual water trade. For this reason, the systematic use of this approach appears promising to help disentangle the complex geography and dynamics of the virtual water network. Finally, the distance-based analysis sets the basis for new insights on the characteristics of virtual water trade and might open the possibility of linking virtual water to the energy consumption required to transport it, allowing for a more comprehensive analysis of the effects of food trade on the environment.

\section{Supplementary material related to this article is available online at: http://www.hydrol-earth-syst-sci.net/ 17/1205/2013/hess-17-1205-2013-supplement.pdf.}

Acknowledgements. Authors gratefully acknowledge Paolo D'Odorico for precious discussions on the topic and comments on the paper.

Edited by: A. Montanari

\section{References}

Aldaya, M. M., Martinez-Santos, P., and Llamas, M. R.: Incorporating the water footprint and virtual water into policy: reflections from the Mancha Occidental Region, Spain, Water Resour. Manage., 24, 941-958, 2010.

Allan, J. A.: Virtual water: A strategic resource global solutions to regional deficits, Ground Water, 36, 545-546, 1998.

Barrat, A., Barthelemy, M., and Vespignani, A.: Dynamical processes on complex networks, Cambridge University Press, New York (NY, USA), 2008.

Bulsink, F., Hoekstra, A. Y., and Booij, M. J.: The water footprint of Indonesian provinces related to the consumption of crop products, Hydrol. Earth Syst. Sci., 14, 119-128, doi:10.5194/hess-14119-2010, 2010.

Carr, J. A., D’Odorico, P., Laio, F., and Ridolfi, L.: On the temporal variability of the virtual water network, Geoph. Res. Letts., 39, L06404, doi:10.1029/2012GL051247, 2012.

Carr, J. A., D’Odorico, P., Laio, F., and Ridolfi, L.: Recent history and geography of virtual water trade, PLoS ONE, 8, e55825, doi:10.1371/journal.pone.0055825, 2013.

Dalin, C., Konar, M., Hanasaki, N., Rinaldo, A., and RodiguezIturbe, I.: Evolution of the globale virtual water trade network, P. Natl. Acad. Sci. USA, 109, 5989-5994, doi:10.1073/pnas.1203176109, 2012.

D'Odorico, P., Carr, J., Laio, F., and Ridolfi, L.: Spatial organization and drivers of the virtual water trade: a community-structure analysis, Environ. Res. Lett., 7, 034007, doi:10.1088/17489326/7/3/034007, 2012.

Feng, K., Hubacek, K., Minx, J., Siu, Y. L., Chapagain, A., Yu, Y., Guan, D., and Barrett, J.: Spatially explicit analysis of water footprints in the UK, Water, 3, 47-63, doi:10.3390/w3010047, 2011.

Hoekstra, A. Y. and Chapagain, A. K.: Globalization of water: sharing the planet's freshwater resources, Blackwell, Oxford (UK), 2008.

Hoekstra, A. Y. and Mekonnen, M. M.: The water footprint of humanity, P. Natl. Acad. Sci. USA, 109, 3232-3237, doi:10.1073/pnas.1109936109, 2012.

Hoekstra, A. Y., Chapagain, A. K., Aldaya, M. M., and Mekonnen, M. M.: The water footprint assessment manual: setting 
the global standard, Earthscan, London (UK), available at: http: //doc.utwente.nl/78458/ (last access: 14 January 2013), 2011.

Mekonnen, M. M. and Hoekstra, A. Y.: The green, blue and grey water footprint of crops and derived crop products, Hydrol. Earth Syst. Sci., 15, 1577-1600, doi:10.5194/hess-15-15772011, 2011.

Montanari, A.: Hydrology of the Po River: looking for changing patterns in river discharge, Hydrol. Earth Syst. Sci., 16, 37393747, doi:10.5194/hess-16-3739-2012, 2012.

Shutters, S. T. and Muneepeerakul, R.: Agricultural trade networks and patterns of economic development, PLoS ONE, 7, e39756, doi:10.1371/journal.pone.0039756, 2012.
Suweis, S., Konar, M., Dalin, C., Hanasaki, N., Rinaldo, A., and Rodiguez-Iturbe, I.: Structure and controls of the global virtual water trade network, Geophys. Res. Lett., 38, L10403, doi:10.1029/2011GL046837, 2011.

Tamea, S., Allamano, P., Carr, J. A., Claps, P., Laio, F., and Ridolfi, L.: Local and global perspectives on the virtual water trade, Hydrol. Earth Syst. Sci. Discuss., 9, 12959-12987, doi:10.5194/hessd-9-12959-2012, 2012. 